\title{
Contemporary Philosophic-Cognitive Area in Metaphor Research
}

\author{
E.R. Mikhailova \\ Foreign Languages Department \\ Ulianov Chuvash State University \\ Cheboksary, Russia \\ elvira.mikhailova@yandex.ru \\ A.G. Abramova \\ Foreign Languages Department \\ Ulianov Chuvash State University \\ Cheboksary, Russia \\ foreign-languages-department@ mail.ru
}

\author{
I.B. Getskina \\ Foreign Languages Department \\ Ulianov Chuvash State University \\ Cheboksary, Russia \\ igets68@gmail.com \\ T.N. Kuznetsova \\ Foreign Languages Department \\ Ulianov Chuvash State University \\ Cheboksary, Russia \\ elre2007@mail.ru
}

\begin{abstract}
The present article considers the approaches of contemporary scientists to metaphor research from the philosophic-cognitive point of view. In contrast to the traditional definition of this trope, the latest metaphor theories by the outstanding philosophers, their distinctive features and significance for science are described and analyzed in this article. Each approach is accompanied with unique examples of the stylistic device in question taken from the works of modern English literature. Each approach reveals a new facet and unique features of this language phenomenon. It should be noted that the theories of outstanding philosophers of the 20th century described above have a solid evidence base, and, therefore, full right to exist. Each of them, in its own way, reveals the essence of metaphor and in its context explains its signs and properties. However, these theories should not be mutually exclusive, but rather complement each other. To limit oneself to only one method of studying a metaphor is the same as looking at the world through a small window and seeing only a small part of it, only a small segment of the horizon, in this case very much can remain beyond the limits of our vision.
\end{abstract}

Keywords - metaphor, philosophic-cognitive, substitution view of metaphor, comparison view of metaphor, interaction view of metaphor, the system of associated commonplaces, literal meaning, absolute falseness, concept.

\section{INTRODUCTION}

For many centuries, the metaphor has been of great interest to philosophers and linguists due to its rich semantic content and unique linguistic potential. It is not surprising that at present there are many views and directions in the study of metaphor. This work aims to analyze the modern philosophical and cognitive direction in the study of metaphor and review the work of some of its most prominent representatives. However, first of all, it is necessary to give the traditional definition of metaphor set forth in the Linguistic Encyclopedic Dictionary in order to clearly understand what the approaches of philosopher scientists to the study of this concept are based on, and also what their innovation consists of. Metaphor (from the Greek metaphora - transfer) is a speech mechanism consisting in the use of a word denoting a certain class of objects, phenomena, etc., to characterize or name an object that is in another class, or to name another class of objects similar to given in any respect.

In a broad sense, the term "Metaphor" is applied to any type of use of words in an indirect sense [1]. This rather capacious definition characterizing the nature of the metaphor allows us to clearly see the structure of the functioning of this trope. Nevertheless, the classical definition of metaphor reveals to us only one facet of this unique linguistic phenomenon. To discover its other facets, we examined modern theories of metaphor from a philosophical and cognitive point of view.

\section{METHODS AND MATERIALS}

For the research, a content analysis of the latest metaphor theories by the outstanding philosophers of the 20th century, Max Black, John R. Searle, Donald Davidson, George Lakoff, Mark Johnson is made. Each approach is accompanied with unique examples of the stylistic device in question taken from the works of modern English literature. Each approach reveals a new facet and unique features of this language phenomenon, such as substitution view of metaphor, comparison view of metaphor, interaction view of metaphor, the system of associated commonplaces, literal meaning.

\section{RESULTS AND DISCUSSION}

We studied how American logician and philosopher Max Black considered this problem. In his classic work Metaphor, Black outlines three views on metaphor, each of which includes and summarizes various theories of the study of metaphor. The first he calls a substitutional view of metaphor [2], according to which a metaphorical expression is always used instead of some equivalent literal expression in the same way as any sentence containing a metaphor is considered as 
replacing a certain set of sentences with direct meaning. The substitutional approach is reinforced by several arguments.

The first of these is the need of the language to fill in the so-called gaps in the dictionary of literal names, since quite often we encounter a lack of a literal equivalent in the language or resort to a suitable abbreviated name. From this point of view, the author considers the metaphor as a kind of catachresis, where the word is used in a new sense for itself in order to denote any new phenomenon or property. The second argument is a certain decorative function of a metaphor. The use of a metaphor instead of a literal expression encourages the reader to unravel the meaning hidden by the author, in other words, challenges the thinking reader. This can be called entertainment or pleasure for the reader, which is important for a literary text. Our research and analysis of the work of modern scholars in the field of metaphorical concepts and theories led to the conclusion that Black somewhat limited the functions of the substitutional approach to the study of metaphor. A metaphor (especially fresh and expanded) quite often carries an emotional subtext and special hidden information. When transmitting any idea, the author encrypts it in a metaphor, thereby increasing its status and value.

The purpose of the author in this case and, accordingly, the function of metaphor: to influence the emotional world of the reader, causing him a strong response to what he read. After all, it is important not only to say, but also how to say it. Any good writer seeks to create a more voluminous vision of the subject, any character traits of a person, emotions, feelings, etc. The metaphor in this case, of course, serves both as a decoration of the text and as a pleasure for the reader, but it also carries a special mission: to influence the reader, arouse his interest, and even captivate him. And this is not always for entertainment purposes. For example, in journalism, fresh and sharp metaphors serve to more accurately and in depth convey information or news. Another metaphor feature that the author did not mention when considering the substitutional approach is the aesthetic enrichment of any serious work of art. As you know, the writing language differs from everyday in the richness of styles, rich descriptions and strong images created using the language.

Any writer always strives to enrich his "language", to make it bright and, figuratively speaking, "voluminous". Indeed, in the work, not only the plot is important, but also the way it is presented. In this a metaphor very often helps the author. And here we are in most cases talking about the author's (fresh) metaphor, regardless of whether it is simple or extended. To prove the above, we will give the following example from the work of J. McEwan "Saturday" (I. McEwan "Saturday"): "Becoming drunk is a journey that generally elates him in the early stages ... But once the destination is met, once established up there on that unsunny plateau, a fully qualified drunk, the nastier muses, the goblins of aggression, paranoia, self-pity take control" [3]. The author describes the usual state of intoxication with a lively and colorful metaphor, creating fabulous images of monsters, which, in turn, allows the reader to fully experience the ugliness of this, alas, an everyday phenomenon. This method of image transmission undoubtedly affects the reader much stronger and more efficiently than the standard set of epithets already known to us. Next, Black presents a second look at the metaphor comparative view [2], where it is argued that the basis of the metaphor is a demonstration of similarity and analogy. In both the first and second approaches, we see that a metaphorical expression is used instead of some literal equivalent.

However, from the point of view of the author, a metaphor cannot be limited to the goal of replacing a formal comparison or any literal statement, since the metaphor has its own special signs and objectives. Black clearly substantiated the following statement: "In a number of cases, it would be more correct to say that a metaphor creates, but does not express, a similarity" [2]. Following the logic of our reasoning, we move on to the third point of view on the metaphor put forward by M. Black, which he called the interaction view on the metaphor [2]. Here we are faced with the concept of the interaction of objects, not ideas. Through the prism of one object, we see another, in a different, new light. Therefore, it is advisable here to speak of a metaphor as a filter. In accordance with the author's theory, we can give the following example. Let us turn to a metaphorical concept: a person is a turtle. Here we distinguish two subjects: the main subject is a person, respectively, the auxiliary subject is a turtle. In this case, the basic role is played by the system of associated commonplaces [2], with which we understand the meaning of metaphor. Many people associate the tortoise with a very slow creature, therefore, when we call a person a tortoise, we automatically endow him with these qualities. But, objectively speaking, few people know what the true natural character of a turtle is, we only know what we are used to know from childhood, having received our ideas from fairy tales and films. In fact, turtles, or rather land turtles, can move on the ground quite quickly and adroitly. There are numerous examples of this. However, this error does not prevent us from understanding the speaker and the metaphor that he creates. It must be remembered that the system of associations does not have to be true, it can be halftruth or complete untruth. The main role here is played, according to Black, "quick activation in the mind" [2] of our ideas about this or that subject or phenomenon. We perceive the main subject through metaphorical expression. At the same time, we should in no case forget about the feedback of this interaction. Calling a person, a turtle, we see him in a special light, however, this also allows us to look at the turtle with different eyes and see something from the person in it. Thus, the real interaction of two objects occurs.

It should be noted that the author, apparently, is inclined to adhere to the latter approach to the study of metaphor, considering it the most comprehensive and complete. This approach, in fact, allows us to identify and analyze some features of the metaphor, however, limiting ourselves to them in scientific research does not seem advisable, as we have already seen earlier. Nevertheless, we can confidently say that the work of M. Black significantly influenced the research of many scientists and allowed them to look at this linguistic phenomenon from a new, unexpected side. The representative of the pragmatic trend, philosopher John R. Searle, takes a slightly different approach to the study of metaphor, which he presented in his work "Metaphor". Searle sees the essence of metaphor in the interaction of the literal meaning of the sentence and the meaning of the speaker's utterance. To 
correctly understand the metaphor, we must clearly distinguish between the meaning of the sentence and the meaning of the statement.

Many researchers are trying to detect metaphorical elements in the sentence itself, trying to divide the sentence into two types: literal and metaphorical. However, according to the author, words and sentences have only the meaning that they were originally endowed with. No additional meaning is needed in them. The metaphor is manifested not in the meaning of the words themselves, but in the context and conditions of the words we use. This is the idea that we put in a sentence or, more precisely, in our statement. It is no accident that the author declares the following: "metaphorical meaning is always the meaning of the speaker's statement" [4]. Here we also find some kind of interaction, but the interaction of meanings. This is a kind of interweaving of literal meanings and figurative meanings in one phrase. The author emphasizes: "The relationship between the meaning of a sentence and the meaning of a metaphorical utterance is regular, not random or arbitrary" [4]. We consider the use of the word "poison" in the work of the modern English writer J. Harris "Chocolate" (J. Harris, "Chocolate"). The original or literal meaning of the word poison is widely known. When analyzing any expression with a given word in our mind, this nominal meaning of the word pops up.

However, depending on the context and the conditions of its application in the sentence, the word acquires an additional metaphorical connotation, in other words, figurative meaning. The word "poison" gets its direct meaning in the following sentence: "I poison the rats which infest the sacristy and gnaw at the vestments there (in the church)" [5]. Then, in other contexts and conditions, we have the opportunity to observe examples of its metaphorical use: "Polite contempt. The barbed and poisonous weapon of the righteous" [5]; "I know he means me harm, but somehow his poison has been drawn" [5]. According to J. Searle, in the above examples of metaphors with the word poison, we see the same word in a new light due to the new context and conditions for its use, but we invariably rely on its literal meaning. Simply put, we proceed from what images the writer seeks to create using the word poison, using it in various semantic situations. Undoubtedly, J. Searle expanded our vision of metaphor, allowed us to go beyond the meaning of the word and slightly change the perception of the already familiar stylistic device, i.e. consider the metaphor from the point of view of its environment in the sentence. Next, we turn to the theory of another philosopher Donald Davidson.

It is of particular interest not only because of its extensive scientific evidence base, but also because of its opposition to many well-known approaches to the study of metaphor, since its position, according to Davidson himself, "goes against the well-known modern points of view" [6]. In his work "What Metaphors Mean", Davidson puts forward his exceptional point of view on a metaphor that challenges many current trends in this field. First of all, the researcher reveals to us the essence of metaphor in the light of the theory of meaning and the theory of truth, arguing that "metaphors mean only that (or no more than that), which means the words that enter into them, taken in their literal meaning" [6]. At first glance, the scientist repeats what was put forward by J. Searle. However, in the course of his thought, Davidson makes a sharp deviation to the side and follows a completely different path. In his opinion, pronouncing a metaphor, we do not communicate anything other than the original or literal meaning of words/sentences in the statement itself. Moreover, the context and conditions for pronouncing the metaphor have no meaning, since, regardless of them, the literal meanings and conditions of truth are unchanged.

Therefore, in the understanding of metaphor, it is the primary or literal meaning of the words that plays the decisive role, and not the additionally attributed or hidden meaning of the phrase. The correct perception of the metaphor is due to the constant interaction of the above literal meaning of the word with the experience of the recipient. This is not the formation of additional meanings, these are the associations and images that are born in our minds through a combination of the meanings of words that we already know. The following example is from the work of the modern English writer N. Hornby "Hi-Fi" (Nick Hornby "High Fidelity"): "See, I've always been afraid of marriage because of, you know, ball and chain, I want my freedom, all that" [7]. In this case, we consider married life (through the eyes of the hero) through the prism of the concepts of bondage, prison, using the expression ball and chain, as well as through semantic opposition to it in the sentence with the word freedom. Thanks to the metaphor created by the author, we clearly imagine how the main character treated family life. Based on the above theory, the writer, making literal statements, makes us see one object as if in the light of another, thanks to which we understand the metaphor.

Continuing his argument, Davidson also draws a parallel between comparison and metaphor, where the former is always true, while the latter is almost always false. Next, we present an example of an artistic comparison from the work of Chocolate, already mentioned by J. Harris: "He is a little like a cat himself, I notice; cold, light eyes which never hold the gaze, a restless watchfulness, studied, aloof" [5]. "He looked like a cat," and this is quite plausible, since for the most part everything is like everything. At the same time, the author could express her thought in a slightly different way: "He is a cat himself, I notice; cold, light eyes which never hold the gaze, a restless watchfulness, studied, aloof. " In this case, we would get a metaphor, and although the idea would not fundamentally change, the statement itself would become false. He looks like a cat, but he is not a cat. Objectively speaking, the statement is not true. However, here, of course, we are not talking about "absolute falsity" [6], but that it should be perceived as false. After all, the metaphor does not distort the main idea of the statement; it only expresses it in a special way. We perfectly understand the absurdity and contradiction of the metaphorical expression, which, in turn, does not allow us to take it literally, but to see it as a metaphor.

In this case, it is worth noting that as soon as the utterance ceases to be false, it accordingly ceases to be a metaphor. Perhaps that is why the falsity of most metaphorical expressions is obvious, and all comparisons are trivially true. All we need, according to the scientist, is not to look for 
something invisible, secret, but to see the obvious. Of course, this point of view is somewhat difficult to accept, since at first glance it may seem rather limited and in some ways superficial; there is no in-depth analysis of the meaning of words and the interaction of meanings. However, the rejection of this approach would mean a significant loss in the field of theories of the study of metaphor, since here we also find a special, unique vision of metaphor, which, without a doubt, reveals another facet of this linguistic phenomenon and certainly deserves our attention. The cognitive theory of metaphor, an innovative and very bold approach for its time in the 80s of the XX century the famous American scientists George Lakoff and Mark Johnson presented in their recognized and extremely popular among a wide audience of readers with the work "Metaphors with which we live." Since antiquity, it was believed that a metaphor is a product and the prerogative of only artistic speech, but for the first time in their work, the authors thoroughly and firmly refute this established point of view, saying that the metaphor literally permeates our everyday life, that it is present in language, thinking and the activities of each person. The concept is that "our ordinary conceptual system within which we think and act is essentially metaphorical" [8]. The authors put forward the idea that the conceptual system of a person is largely metaphorical, since the way we think, what we learn from experience, and what we do every day, are directly related to metaphor. The concepts that control our thinking influence our daily activities, down to the smallest detail. These same concepts include our feelings, behavior, attitude to other people in a single system. However, the authors here are not limited to theoretical considerations and enrich their work with examples of various conceptual metaphors, proving that all life literally consists of them, and most often we simply do not realize this. In accordance with the foregoing, we will present the following conceptual metaphor to the readers' judgment: The city is a Living Organization. In various languages of the world, we can meet many erased and fresh metaphors built and structured on the basis of this concept. In our work, we turn to examples of dead (erased) and fresh metaphors in English and Russian. First of all, it should be noted that in everyday speech we often turn to the concept of City - it is a Living Organism, without even thinking about it. You can consider the following examples of the erased metaphor: - $\mathrm{He}$ has been swallowed by the city. - The city has woken up. The city has finally fallen asleep. Further we will consider examples of fresh, author's metaphor. The aforementioned English writer J. McEwan in his work "Saturday" repeatedly refers to the concept City is a Living Organism, since the city in its work is one of the main characters; he's as if revived. 1. "But a city of its nature cultivates insomniacs; it is itself a sleepless entity whose wires never stop singing ..." [3]. 2. The city's appetite for Saturday work is robust. At six o'clock, the Euston Road is in full throat [3]. 3. The street is fine, and the city ... is fine too, and robust. It won't easily allow itself to be destroyed. It's too good to let go [3]. 4. The foot, like some roughneck hick town, is a remote province of the brain, liberated by distance from responsibility [3]. 5. Sick buildings, in use for so long, that only demolition can cure [3].

The authors argue that "the essence of a metaphor is understanding and experiencing the essence of one kind in terms of the essence of another kind" [8]. We must not forget that the city and the human body are completely different entities that belong to different classes of concepts, nevertheless, we often understand and talk about the city in terms used to denote the human body. And in this case, the method of describing the city involves the use of a metaphor, which we most often do not realize. However, it is invariably present both in our everyday speech and in creating fresh, author's metaphors. It follows from this that, according to the opinion of J. Lakoff and M. Johnson, the metaphor of the processes of human thinking is obvious. The point of view of J. Lakoff and M. Johnson on the study of metaphor seems to us quite reasonable and, no doubt, logical. It provides a voluminous and comprehensive explanation of metaphor as a linguistic phenomenon, its properties and functions. This is its phased systematization, as close as possible to the real life of a person, which allows us to understand it so easily and quickly and, importantly, to accept it. The versatility of the metaphor is truly inexhaustible. The process of studying it has no conventions and boundaries.

\section{CONCLUSION}

Based on the analysis of newspaper texts, we can draw the following conclusion: Each approach reveals a new facet and unique features of this language phenomenon. It should be noted that the theories of outstanding philosophers of the 20th century described above have a solid evidence base, and, therefore, full right to exist. Each of them, in its own way, reveals the essence of metaphor and in its context explains its signs and properties. However, these theories should not be mutually exclusive, but rather complement each other. Undoubtedly, this or that point of view will always be closer and clearer to us. However, to limit oneself to only one method of studying a metaphor is the same as looking at the world through a small window and seeing only a small part of it, only a small segment of the horizon, in this case very much can remain beyond the limits of our vision.

\section{References}

[1] V.N. Yartseva , Linguistic Encyclopedic Dictionary, M.: Sov. Encyclopedia, 1990, p. 668

[2] M Black, Metaphor. Theory of metaphor: a M.: Progress, 1990, p. 512

[3] I. McEwan, Saturday, L .: Vintage, 2006, p.279.

[4] J.R.Searle, Metaphor Theory of metaphor: M .: Progress, 1990, p. 512

[5] J. Harris, Chocolat, L .: Black Swan, 2007, p.320.

[6] D. Davidson, What do metaphors mean Theory of metaphor: collection M.: Progress, 1990, p. 512.

[7] N.Hornby, High Fidelity, L .: Penguin Books, 2000, p.245.

[8] J.Lakoff, M.Johnson, Metaphors with which we live: Trans. from English M.: LCI, 2008, p.256.

[9] J. Zinken, "Discourse metaphors: the link between figurative language and habitual analogies”, Cognitive Linguistics, vol. 18, № 3, p. 445-466, 2007.

[10] L. Wee, "Proper names and the theory of metaphor", Journal of Linguistics, vol. 42. № 2, 2006, p.371.

[11] N. Desrochers, A. Paul-Hu., S. Haustein, P. Mongeon, V. Larivière, R. Costas., A. Quan-Haase, T.D. Bowman, J. Pecoskie, and A. Tsou, "Authorship, citations, acknowledgments and visibility in social media: symbolic capital in the multifaceted reward system of science," Social sciences information, vol. 57, No. 2, 2018, p. 223-248, 
[12] S.Coulson, "Michiel leezenberg, contexts of metaphor (current research in the semantics/pragmatics interface", Amsterdam: Elsevier, Journal of Linguistics, vol. 39. № 3, 2003, p.704-706.

[13] M.A. Gernsbacher M.A., B.Keysar, R.R.W.Robertson, "The role of suppression and enhancement in understanding metaphors", Journal of Memory and Language, vol. 45. № 3, 2001, p. 433-450.
[14] B.Keysar, Y.Shen, S.Glucksberg, "Conventional language: how metaphorical is it?" Journal of Memory and Language, vol. 43, № 4 , 2000, p. 576-593.

[15] E. Barbé, A.Herranz-Surrallés, M. Natorski, "Contending metaphors of the European union as a global actor: norms and power in the European discourse on multilateralism", Journal of Language and Politics, vol. 14, № 1, 2015, p. 18-40. 